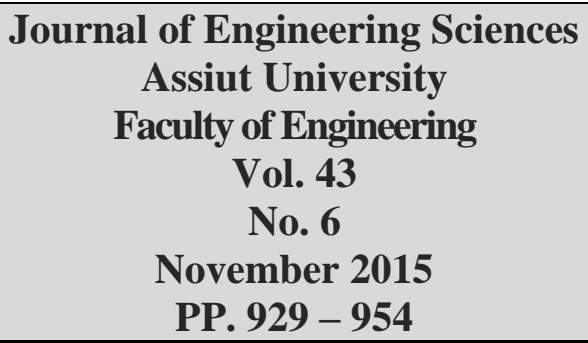

\title{
THE ROLE OF NATURE FORM VERSUS LIFE PRINCIPLES IN ACHIEVING SUSTAINABILITY OF BIO-MIMIC ARCHITECTURE: MEASURING THE GAP OF CONTEMPORARY EGYPTIAN PRACTICE OF BIO-MIMIC ARCHITECTURE
}

\author{
Islam Ghonimi Ibrahim \\ Faculty of Engineering Shoubra - Benha University \\ islamghonimi@yahoo.com, islam.ghonimi@feng.bu.edu.eg
}

(Received 17 September 2015; Accepted 21 October 2015)

\begin{abstract}
Architecture manifestation of nature is not new; through history, architects try to manifest nature, they always consider nature as big source of inspiration. The last few decades witnessed a scientific revolution caused deep understanding of nature form and life principles. Many Architects tested the contributions of such principles to architecture they ranged their manifestation of such principles between achieving form and performance oriented architecture. This research investigates the role of nature form versus life principles in achieving sustainability of nature, and how that can be reflected on architecture sustainability; with special reference to evaluate and measure the gap of contemporary Egyptian architecture manifestation of nature.
\end{abstract}

To achieve this goal the research go through interlocking steps, first the nature form and life principles are investigated and their reflections to architecture are documents. Second the impacts of nature form and life principles on nature sustainability are investigated and their reflections on architecture are documented. Fourth, different evaluation criteria are deduced and used to deduce different approaches of architecture manifestation of nature in term of form vs. life principles and Formal vs. Performance oriented manifestation. Finally: The deduced criteria and classification are used as evaluation tool to measure the gap between theory and contemporary Egyptian practice of architecture manifestation of nature.

The study concluded to deduce five modes of architecture manifestation of nature; they are ranged between complete biomorphic formal oriented architecture and complete bio-function performance oriented architecture. It also concluded how big is the gap between theory of bio-mimic architecture and contemporary practice in Egypt.

Keywords: Form principles vs. Life principles; Bio-mimic; Form vs. Performance Concerns; sustainability; Bio-morphic vs. Bio-logic vs. Bio-kinetic vs. Bio- morphological.

\section{Introduction (why nature?)}

Bio-mimicry is a contemporary field that provides an umbrella used to describe the practice of mimicking Bases from the natural world to design the manmade artificial world [1]. Many architects consider nature as great professor; they inspired by nature to 
transform its wisdom and principles into successful design. They consider nature as big source of ideas and inspiration for their designs from nature. Nature has founded with solutions for many problems we are trying to solve, the matter that make it able to survive for long time. Nature could sustain itself; it can provide successful examples that figured out materials, forms, processes, systems needed to sustain themselves to survive to today.

Benyus in her book "Bio-mimicry: Innovation inspired by nature" argued that with nature, a sustainable world already exists; we just need to open our eyes to see answers for sustainability around us. She considers nature wisdom to be on the shaping of the future [2]. Biomimetic architecture is a contemporary philosophy of architecture that seeks solutions for sustainability in nature. It is a multi-disciplinary approach to sustainable design that follows a set of principles rather than stylistic codes.

In the last decades a more scientific evolutions have caused a transition from mechanical reductionist to natural holism deep understanding of nature form and Life principles; The matter that are reflected on architecture form by using non-Euclidian, fractal, self-similar, replicated, differentiated and dynamic form, that give rise to a massive trend in architecture manifestation of deep understanding of nature form principles. On the other hand, Nature offers more than forms it is about the Processes of generation of form. It is about life that makes livable bio inspired buildings behave in a self-organized, self-resembled, selfsustaining, livable and spontaneous procedure guided by biological lows of selection.

\subsection{Research Problem}

Many scholars discussed the role of bio-mimic in achieving sustainability in architecture. But still a massive debate come rise about the role of nature form versus life principles in archiving sustainability, that need in-deep exploration for their roles in achieving sustainability. Besides, the current practice of contemporary architecture witnessed some trials of manifestation of nature; they lose the main aim of achieving sustainability. There is a need to be evaluated and tested to define their efficiency and classifications.

\subsection{Research aim}

The main goal of this research is to use interdisciplinary based research to recognize nature form and life principles and to explore how to incorporate them in architecture in order to acquire nature efficiency, intelligence and sustainability. The research arguments the debate of the role of nature forms versus life principles to achieve aesthetical versus functional concerns. It aims to theorize the modes of architecture manifestation of nature as function in form vs. life principles, and ethical vs. performance concerns. This will pave the way to measure the gap of contemporary Egyptian practice of architecture manifestation of nature.

\subsection{Research methodology}

To achieve this goal, this paper goes through five interlocking stages. The first is to introduce natural form and life principles. The second is to describe how to apply those principles in architecture. The third is to introduce a comparative analysis between their impacts on architecture sustainability. The fourth is to deduce different approaches of architecture manifestation of nature in regard to form vs. life principles and Formal vs. Performance oriented concerns; finally, this classification is used to judge and measure the gap of Egyptian contemporary modes of architecture manifestation of nature. 


\section{Nature}

Nature can be seen as independent of manmade. Nature is given from God Allah; God creates nature in appropriate manner to be suitable for their context. Nature behaves in the manner God inspires in them. Nature can be found in a biological form in living organism like animals, faunas, accents, floras, and plants, or it can be a manifestation of topological form like mountains, waves, sand, Dunes and hills [1 ]. Nature refers to two interlocking components form and life, on the first hand it concern physical world that constitute their natural forms, in nature form follow function. On the other hand it concerns nature life that constitutes their functions, performance self-behavior and self-actuation to survive and sustain itself. The next part will discuss how deep understanding of nature form and life can achieve nature sustainability and how can it impact modes of architecture manifestation. The research concerns the common general principles of the form and life of all nature living entities, regardless of the differentiation of nature elements in different environments.

\subsection{Nature form principles}

Nature form is the physical part of nature. The physical form of the organism enables him to behave in a certain way to achieve his life goal and to achieve self-sustaining process. This form is changing with different functions and in different environments to enable the living organism to behave in a right way according to the life conditions. Regardless the differentiation of nature elements in different environments, nature form has common general principles called the fractal geometry.

Mandelbrot, a mathematician natural scientist, discovered the fractal geometry of nature with self-similarity; he argued that natural geometry is not Euclidian rather it is a fractal non-Euclidian geometry. He stated that "Clouds are not spheres, mountains are not cones, coastlines are not circles, and bark is not smooth" [3]

According to Mandelbrot natural geometry is completely deferent from artificial human geometry. Different aspects make it different. Mandelbrot and others introduce a new different explanation of nature that is different from old classical models. Through analysis of coastline, Mandelbrot found the field of fractal geometry, which models the recurrence of similar patterns at different scales which characterizes most natural systems. He argued that these aspects are extended to every natural form [3].

He concluded that Euclidian geometry are insufficient to explore the universe, it cannot interpret the hidden behavior and deeper order of nature. He discovered the so-called Fractal Geometry or Mendelbortian geometry, considering the universe is full of insects, plants, animals, and many other natural forms that all share the same nature geometry and hidden order of self-similarity, replication, differentiation, nonlinearity, self-organizing, and uniform. Architects are leaders, who have to reflect the changing explanation of nature. According to Venturi, architects are similar to biologists in concerning world syntax. As our understanding of nature increase, architects trey to reflect these new deeper understands of nature.

In the next part, different scientific concepts that differentiate artificial geometry from natural geometry are explored and compared. These concepts are projected to architecture distinguish between the classic and complexity architecture manifestation of nature. The development of scientific revolution in its interpretation of nature discovered different 
Islam Ghonimi Ibrahim, The role of nature form versus life principles in achieving sustainability ...

principles for nature form, that make it different form old perceived reductionist view of mechanical sciences. These principles can be perceived in the following:

\subsubsection{Euclidian Vs. Non Euclidian Geometry:}

Non-Euclidian geometry is a natural form principle that replaces the old mechanical Euclidian Geometry. According to Mandelbrot, the nature geometry is not a Euclidian geometry, rather it is a non-Euclidian geometry, and it is fractal or Mendelbortian geometry. The complexity interpretation of Nature Geometry is not geometry of flat space; rather it is geometry of curved spaces. It is not geometry of rectilinear shapes that depend on straight line, rigid hermitic geometry; rather it is geometry of curvilinear shapes that depend on spines, blob, nurbs, and particles. Figure 1 explores the difference between Villa Savoy that had artificially manifested nature form with Cubes and flat spaces; and Ronchamp that had naturally manifested nature form with nurbs and curved spaces, [4].
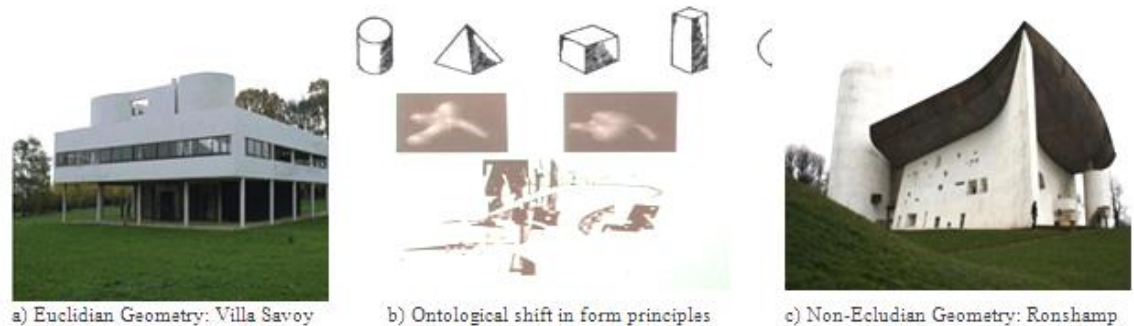

Fig. 1. Euclidian vs. Non-Euclidian Geometry in Architecture

\subsubsection{Self-similarity vs. self-sameness}

Self-similarity is a main natural form principle that replaces the older mechanical concept of self-sameness. It is similar to a part of itself (i.e. the whole has the same shape as one or more of the parts. Mandelbrot argued that coastlines like many objects in the real world which are statistically self-similar: parts of them show the same statistical properties at different scales [5]. He argued that the universe is full of self-similar organism in plants, insects, animals, and many other natural organisms [3]. Figure 2 explores the difference between Montreal complex of Moshe Safadi who artificially manifested nature form with selfsameness; and Ramot neighbourhood of Ashton Ragatt who naturally manifested nature form with Self-similarity [4].
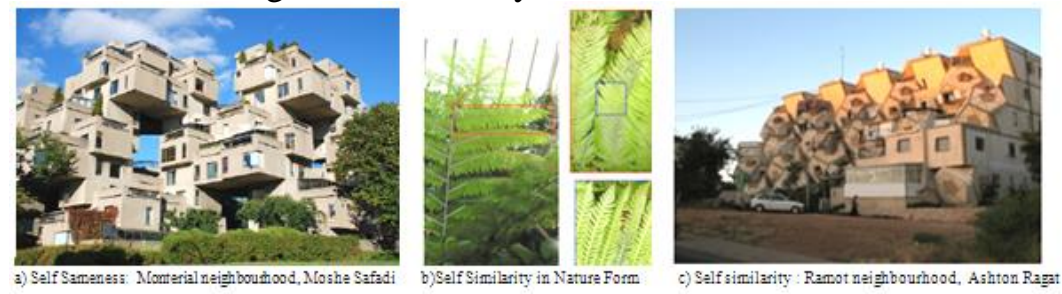

Fig. 2. Self-similarity vs. Self-sameness in architecture

\subsubsection{Replication vs. Repetition}

Replication is another natural form principle that replaces the older mechanical concept of repetition [4]. The complexity of natural tissue is not regularly repetitive geometry of self-same objects; rather it is irregular change over time in unit size, direction, and order. Replication has been studied as the process of natural growing an object while altering its properties to produce a whole. Figure 3 explores the difference between Modern complexes of Le-Corbusier who artificially reduced the manifestation of nature form in 
repetition; and Stone Tower of Zaha Hadid who replicated the self-similar units in irregular syntax of size, direction, and order to achieve a holistic entity.

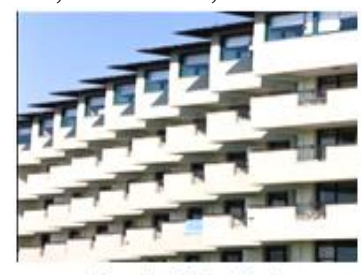

a) Repetition: Moden Hotel

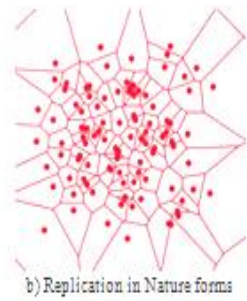

b) Replication in Nature form:

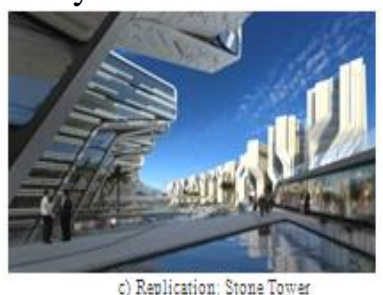

c) Replication: Stone Tower

Fig. 3. Repetition vs. Replication in architecture

\subsubsection{Differentiation vs. difference}

Differentiation is another natural concept that replaces the old mechanical concept of pure difference. The complexity differentiation is the process of gathering parts of a whole to achieve uniformity and avoid diversity [4]. Figure 4 explores the difference between artificial reduction of the manifestation of nature form in Difference; and the differentiated self-similar units in irregular syntax of size, direction, and order to achieve a holistic entity.

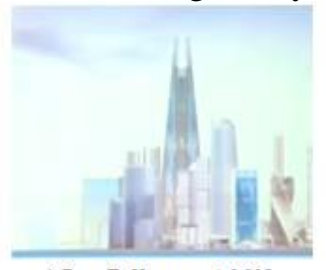

a) Pure Difference: A.M.N

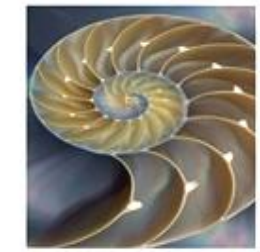

b) Differentiation in Nature Forms

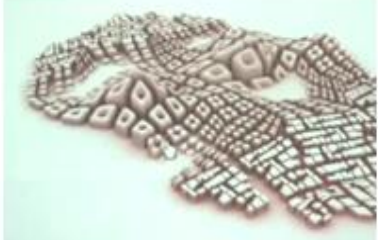

c) Differentiation: N.M.N

Fig. 4. Difference vs. Differentiation in architecture

\subsubsection{Dynamic form vs. static form}

Dynamic Behaviour is another natural concept that replaces the old mechanical concept of static behaviour. Natural forms are not mechanical static rather it is natural growing one. Static system is the process of gathering parts together. Mechanical static things are made such as machines, are an assemblage of parts put together, or shaped, like sculpture, from the outside inwards. Nature form is evolutionary and growing, which grow shape themselves from within outwards - they are not assemblages of originally distinct parts. They partition themselves, elaborating their own structure from the whole to the parts, from the simple to the complex [6].

The complexity model of dynamic system have an evolution fixed rule, that describe the time dependence of point in a geometrical space, the rule describes what future state follow from the current state. Different rule are depending on Strange Attractor. Where an attractor is a set towards which a variable, moving according to the dictates of a dynamical system, evolves over time. Figure 5 explores the difference between static behaviour of early trials of Bruce Guff compared to the dynamic behaviour of Zive Heiker in Heinz Galinski School.

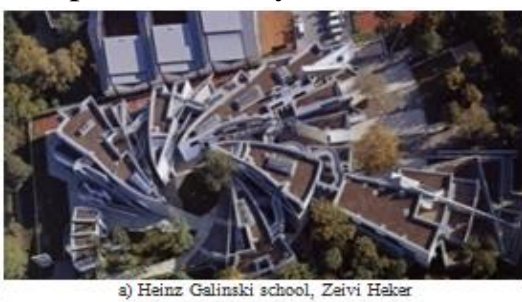

Fig. 5. The Attractors in Architecture

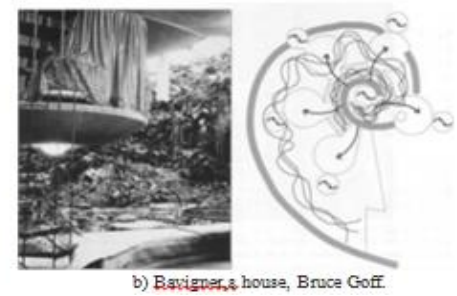


The unique form principles of nature are rooted in the fractal geometry developed two main concept the malleability and mass customization. To achieve this aims nature need to cross mass production and go through form customization, self-similar rather than selfsameness, differentiated rather than difference, and replicated rather than repeated. This enables form to be malleable.

\subsubsection{Mass production vs. mass customization}

Mass customization presents an alternative for mass production that based on repetition, symmetry, and self-sameness. Mass customization presents alternatives, variety selfsimilarity and differentiation. Its core is effectively postponing the task of differentiating a product [7]. Figure 6 shows the difference between Kisho Kurokawa mass productive form and Eco-Pods mass customized form.
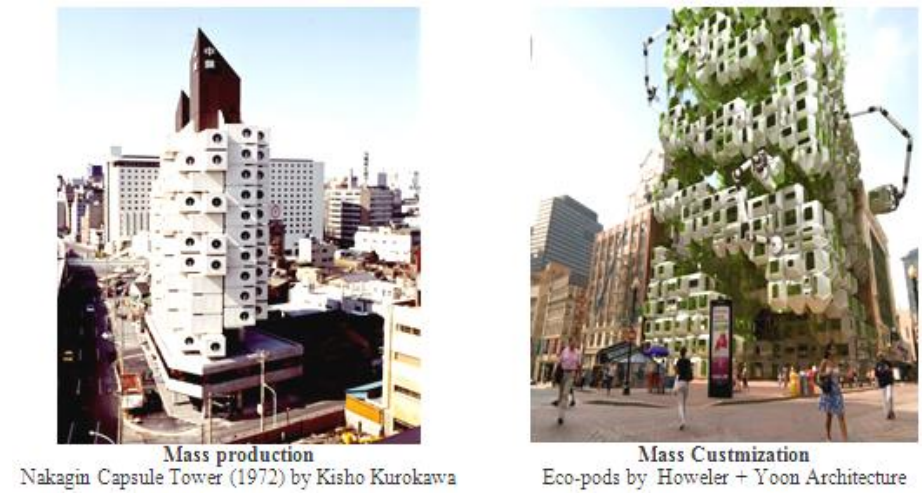

Fig. 6. Mass production vs. Mass Custmization in Architecture

\subsubsection{Rigidity vs. Malleability}

Malleability presents an alternative for Rigidity; rigid objects is unchanging container of unchanging objects, unlike malleable objects that refers to acknowledge an object's capacity for change in response to a force, a universe of varying dimensions [8]. It is to be capable of being extended or shaped by pressure from rollers to change from state to other state.

Self-similarity, differentiation, replication and mass customization of nature form provide it with high malleability for altering nature to make it evolve, adoptive and growing with different shapes into other states. Figure 7 shows how malleability presents main factor in nature life principles, it makes nature able to be movable under pressure and react with actuators under change in circumstances.

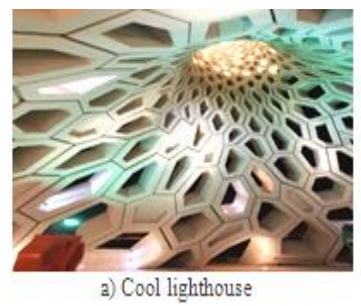

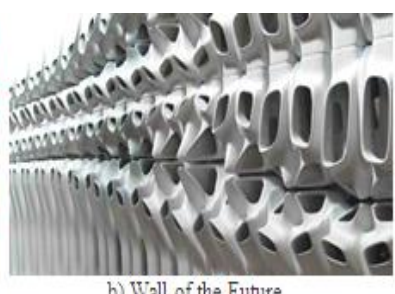

b) Wall of the Future

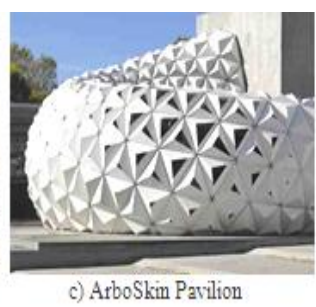

c) ArboSkin Pavilion

Fig. 7. Mass customization lead to malleability in Architecture

\subsubsection{Modes of architecture manifestation of nature form}

Based on the previous analysis, it is evident that Nature systems are not a mechanical system. The old mechanical explanations of nature are insufficient to explain the complexity 
JES, Assiut University, Faculty of Engineering, Vol. 43, No. 6, November 2015, pp. 929 - 954

of nature. A new principle are required to meet the new standards of reason, most of geometrical principles are changed into a more complexity explanations. Table (1) concludes the main key differences on modes of architectural manifestation of nature (Artificial versus Natural Modes): self-sameness vs. self-similarity, repetition vs. replication, difference vs. differentiation, diversity vs. uniformity, dynamic vs. static, Euclidian vs. non-Euclidian.

Table 1.

The difference between natural vs. artificial manifestation of nature Form

\begin{tabular}{|l|l|}
\hline Mechanical Manifstation of Nature Form & Natural Manifstation of Nature Form \\
\hline Form in The Machine World & Form in The Natural World \\
\hline Euclidian Geometry & Non Euclidian (Fractal) Geometry \\
\hline $\begin{array}{l}\text { Rectilinear / Flat shapes } \\
\text { finear, rigid/hermetic geometry }\end{array}$ & $\begin{array}{l}\text { Non- rectilinear /curve. shapes } \\
\text { Spines, blobs, nurbs, particles } \\
\text { Dynamic, and differentiated. }\end{array}$ \\
\hline Self-sameness static & Self-similarity \\
\hline Repetition & Replication \\
\hline Uniformity & Diversity \\
\hline Difference & Differentiation \\
\hline Reductionist (separate elements) & Holistic (Parts of a whole) \\
\hline Regular & Irregular \\
\hline Static & Dynamic (strange attractor-correlation) \\
\hline Rigid boundaries & Non-rigid boundaries \\
\hline Mass Production & Mass Customization \\
\hline Rigid & Malleable \\
\hline
\end{tabular}

\subsection{Nature life principles}

Different scientific comities worked to discover the principles of nature life; one of these comities is bio-mimicry institute ${ }^{\mathrm{i}}$. They developed life's principles guild. It contains 6 major aspects that achieve life function. This research concentrates to the main aspects of having actual life resembled in self-behaviour movement of nature.

Nature life is the way that particular types of things exist and change of their own accord. Life distinguishes objects that have self-behavior from that do not [6]. Life provides nature living entities the principals of movement and change. Mostly the self -behavior is the way living objects act to be self-adopted, self-evolve and self-organized according to the changing conditions to meet performance requirements. Living self-sustaining systems have the ability to adjust to the fluctuating internal system and external environment. Living objects responses to changes in environment conditions and presents opportunities for performance oriented architecture manifestation. Living systems undergo metabolism, they always have the capacity to grow, respond to stimuli and adapt to their environment in successive generations. 
This can inspire architect of more than such form finding, it inspires architects about nature life, about the biological and ecological behavior of nature to survive. This help them to build sustainable and ecological built manmade environment that is responsive utilizing the dimension, assembly, and malleability induced by external influences like air pressure, temperature, humidity, air pollution and solar radiation, and internal functional requirements.

Life is a self-behaviour that distinguishes objects with self-organized, self-resembled from other with controlled behaviour. Life means to sense, and give self and spontaneous response in the process of change and growth. Life has its own principles to create conditions conducive to life. The self-behaviour is a matter of intelligence of living organism [9]; it is a complex internal operation to achieve adoptability with the context.

\subsubsection{Natural intelligence}

Having life means to sense of internal system relations and the external eco-system and to react to stimuli's of the system and to change in ecosystem and responds to it, with change and growth. Feedback loops, integrate the unexpected, reshuffle information and maintain integrity, interconnectivity, interdependent, and cooperation relationship. Life is to react, self-organize, adopt, and evolve to change, and self-resembled. Living entities response and adopt to internal factors and external changing condition using its intelligence in 3 stages, sense, think, and adopt:

\subsubsection{Stimuli using sensing devices}

Sensors and detectors are sensing devices in nature that is methods of collecting information and data for different variables and changes inside and outside. It gives information regarding surrounding environment just like temperature, humidity, sunshine, wind, air flow, or give information about the motion in the outside.

\subsubsection{Decision through control devices}

It is a thinking and controlling device using its natural intelligence learning from previous experiences to take decision of optimum response.

\subsubsection{Response through actuation mechanism}

Response can be assembled by the actuators, development, distribution and organization of the malleable self-similar, customized replicated form. The way they assembled defines the extent of optimization to the change of internal factors and external conditions.

Accordingly, three interlocking principles are characterising nature life. The first is that it is not stand alone entities, it is part of a complex system inside an ecosystem; a double impact exists between it and its eco-system, it is interdependent, interaction, and integration with its context. The second is their adaptation and evolvement to meet the short term changing conditions of the system and ecosystem. The third is their evolution and growth to meet the long term changing conditions of the system and ecosystem.

\subsubsection{Reductionist vs. Holistic}

Nature cannot be reduced to a reductionist view to consider object as separate standalone entities, rather it should be considered in a holistic view that are composed as parts of a whole that has multi interconnected, interacting and integrated functions. Nature is not about form; nature is a form that is governed with system. Nature is not a standalone entity; rather it is a system consists of parts of an integrated whole system with in an eco-system. 


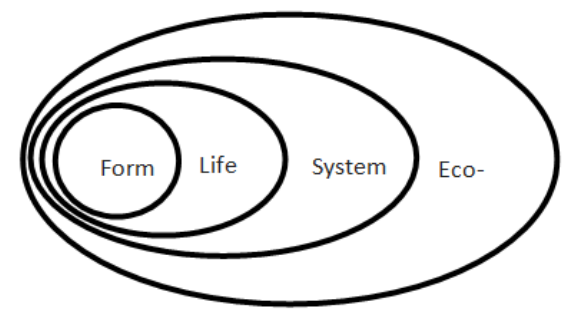

Fig. 8. The complexity of Nature as a system in an Eco-system

\subsubsection{Complex system versus Simple systems}

Nature is a System, that behaves in nonlinear, non-hierarchical manner that make nature behave in interdependent, cooperative, interconnected, and multifunctional manner. Nature is self-organized to achieve equilibrium. Nature life is a complex system, has relationships between its parts that give rise to the collection behaviour of a system and how the system interacts and forms relationship with the environment. Finally, Nature is a system in an ecosystem, it is a set of interacting or interdependent components forming an integrated whole. It is described by its structure and purpose and expressed in its functioning. It is surrounded and influenced by its ecosystem.

Nature as system has structure [10]; it contains components that are related to each other. It has behaviour and exhibits processes that fulfil its function or purpose. it has interconnectivity, the parts and processes are connected by structural and/or behaviour relationships. It may be decomposed via subsystems and sub-processes to elementary parts and process steps [10]. It has behaviour that, in relativity to its surroundings, may be categorized as both fast and strong, as shown in Figure 6. The complexity of the system stems from the following characteristics, Surface versus deep organization, Linear versus non-linear organization, Single function versus Multifunction.

\subsubsection{Surface vs. Deep organization}

Organization depth is a natural life principle that replaces older mechanical surface organization. The complexity organization concerned with deep organization that imputes a multilayer's of subsets to create one entity. The depth depends on hierarchy combined by subsets of rank size in which large elements are less in numbers as compared to small size elements. Hierarchy is a power law relationship between elements with different sizes, which creates the whole [11] [12].

Deep organization consists of different subsets each one of these subsets is a set of elements by some sort of inner bending force. A deep relation exists between these subsets that make the collection of these subsets much deeper than the classical surface one. For example the universe (stars, planets, and moon) orbits. The multilayer system achieves complexity when each layer interlinks, interact, and influence with other layers at different levels, to create deeper organization of structure.

\subsubsection{Hierarchy vs. Non- hierarchical system}

Non-Hierarchical is another natural concept that replaces the old mechanical concept of Hierarchical, as a way of creating a set of elements which is belonging to each other. The classical Hierarchical system is a tree like; its subsets do not meet or interact with each other. The complexity natural non- Hierarchical that its subsets overlap, interact, and influence each other, and create connections between internal sub-elements. Type of 
Islam Ghonimi Ibrahim, The role of nature form versus life principles in achieving sustainability ...

structure creates the difference between the classical structure in which no overlap occurs and the complexity ciaos structure in which overlap occurs [13].

\subsubsection{Linearity vs. Non-linearity system}

Non-linearity is another natural concept that replaces the old mechanical concept of linearity. The complexity natural non-linearity change is clear in most physical systems that are inherently nonlinear in nature. They obey the nonlinear equations like inverse square low. They are complex systems that inherently interact at different levels [13].

To conclude the nonlinear, non-hierarchical, and organizational depth are principles of the holistic system enables living entities to sense of the complexity of system and ecosystem impacts, and so have self- behaviour to achieve integration, interdependency and interconnectedness within the system at multi-layering, multi levels, and multifunction, and have the reason to animate to meet the new conditions of the environment.

\subsubsection{Mechanical behavior vs. Spontaneous (self-behavior)}

The second factor of life is the spontaneous behaviour of nature that depends on selforganizing and Adoptive evolving system to meet the complex impacts of internal system and external ecosystem.

\subsubsection{Controlled vs. Self-organizing}

Self-organization is another natural concept that replaces the old mechanical concept of controlling. The complexity interpretation of nature concerned with self-organizing which is spontaneous process of organization, change and evolution without control of any external system, on the basis of the same variation and natural selection processes. A spontaneous creation of an "organized whole" out of a "disordered" collection of interacting parts, as witnessed in self-organizing systems in physics, chemistry, biology, sociology is a basic part of dynamical emergence.

It emulates self-organization processes in nature by developing a fibre composite that can sense, actuate and efficiently adapt to changing environmental conditions. Such selforganization of nature is to achieve equilibrium between two interlocking forces, the external (environmental conditions) and internal shape, structure, and function.

\subsubsection{Fixed vs. Adoptive and evolved}

Adaptation is a common life principle that enables Nature to move and evolve to survive, in response to system change to meet new performance requirements. Nature form geometry principles encourage change with movement, compared to static Euclidian geometry. The self-similarity, replication, and differentiation nature form geometry can achieve malleable customized fibres that can be moulded into complex shapes. This power of nature form responds to performance requirements through the customization; as conditions change, features are further customized to meet new performance requirements through the natural growth process. Nature Fractal forms provide good structure that react with force and aero-dynamics, wide in and narrow in another areas, it benefits malleability and fabric of nature form to achieve stability. Nature form malleability provides the capacity for change in response to a force.

Through automation, this now more malleable form of architecture is able to compete with standardization in terms of manufacturing efficiency; eliminating the comparative 
advantage of mass production over mass customization. Adopt, evolve and control environment through passive systems, the adjustment of form, and shell patterns.

Figure 9 explores different examples considering nature life beauty emerges from the power of their system to continually evolve and adapt to changing conditions efficiently and elegantly weaving a complex web of simple solutions. Sensors, monitoring, and feedback loop systems. The self-organizing behaviour, with system complexity, adoptability, interdependency and evolvement based on metabolic form that is created from the differentiation and replication of self-similar compositional elements, by the gathering and expenditure of energy. 'Thigmomorphogenesis' refers to the changes in shape, structure and material properties of biological organisms that are produced in response to environmental change [14].

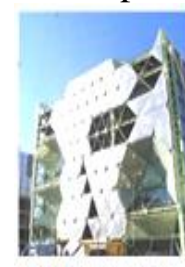

ETFE cushions

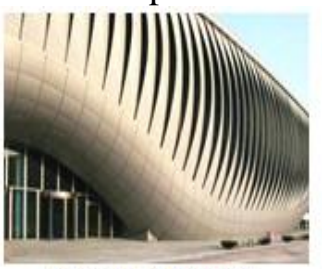

One Ocean Pavilion

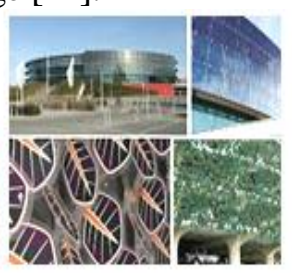

3Gatti's Francesco Gatti

Fig. 9. Examples of adoptive evolving architecture.

\subsubsection{Modes of architecture manifestation of nature life}

Based on the previous analysis, it is evident that the formal explanations of nature are insufficient to explain the complexity of nature. Form and life principles are required to meet the new standards of reason. Table (2) concludes the main key differences on modes of architectural manifestation of nature (Artificial versus Natural Modes): Linearity vs. Nonlinearity, Hierarchy vs. Non-hierarchy, controlled vs. self-organized, surface vs. deep organization, fixed vs. adoptive and evolving, Maximize vs. Optimized.

Table 2.

The difference between natural vs. artificial manifestation of nature Function

\begin{tabular}{|l|l|}
\hline Mechanical Manifstation of Nature Life & Natural Manifstation of Nature Life \\
\hline Mechanical systems that explain physical world & Self-organizing systems that explain natural world \\
\hline Reductionist (separate elements) & Holistic (Parts of a whole) \\
\hline Simple entities & Complex system \\
\hline Surface organization & Organizational depth (Multifunction - multi layers \\
\hline Linearity & Non-Linearity \\
\hline Hierarchical & Non- Hierarchical \\
\hline Dependent & Interdependent - interconnected \\
\hline Mechanical behavior (Oriented Behavior) & Spontaneous behavior (self-behavior) \\
\hline Controlled & Self-Organizing - Self- resembled \\
\hline Fixed & Adoptive and Evolving \\
\hline Static & Dynamic \\
\hline
\end{tabular}




\section{Sustainability of nature form and life principles}

After reviewing nature form and nature life principles, a current contradiction is raised about the role of nature form and life in achieving sustainability. In this part we will discuss the contribution of both principles in achieving nature sustainability. Three main cores of environmental sustainability required to achieve environmentally friendly architecture:

- Efficient Consumption of resources; which includes energy, water, land, and material resources; this includes the use, reuse, store, recycle, reserve, and gather resource.

- Environmental Protection, which includes low emission of pollution, and keep nature.

- Protecting occupant health and increasing their productivity by enhancing the Indoor environmental quality, which includes thermal comfort, illumination, acoustics, air quality and ventilation; this includes the regulation and control of their impacts on the building.

In this part we will discuss how can nature form and life deep principles achieve sustainability and can improve, sustain and survive of building environmental adjustment, energy consumption and structure.

\subsection{Buildings inspired by nature in environmental adjustment}

Environmental adjustment is the processes of Control, responsive and regulation of external impacts of day light, air pressure, temperature and heat transition, humidity impacts, air pollution, sunlight, solar radiation and water loos. In this process nature regulates entry of daylight, controls the entry of sun light and regulates internal temperature, like stomata of leave or Iris of eye; it acts as sound buffer or insulation, like Cushion effect of Birds nest; it provides ventilation mechanism and effective channeling of wind, like termite molds for channeling air. The surface automatically positions itself according to the sunlight and let it in Surface absorbs water and converts waste to biogas energy. Electricity not required during day. Air and wind filtered to provide clean air and natural air conditioned, and Recycling of water air and waste.

Nature has such ability, it gives architects inspiration; both building skin and nature skin are subjected to similar environmental conditions. Fabrication of contemporary nature like facade can achieve the performance of biological world. Nature organisms are capable of surviving in their ecosystems by virtue of their form and life principles, as follow:

\subsection{The role of nature form principles in environmental adjustment}

The strong correlation between biological forms and mechanical phenomena ${ }^{1}$ achieve this goal through the self-similar, replicated, and differentiated skin that give the nonlinearity of Fractal and malleable forms that can reduce the surface temperature by increasing turbulent air flow over the boundary air [15]. On the other hand this kind of complex network full of loops enhances distribution network flow of liquids. The fluctuating difference between different parts gives the ability to find air follow between its part, even though there is no air flow in the environment [16]. This ensure the flow isn't stopped, and can go everywhere in the network as shown in Figure 10.

\footnotetext{
${ }^{1}$ [Thompson 1917, Turing 1954, Durgun 2007].
} 


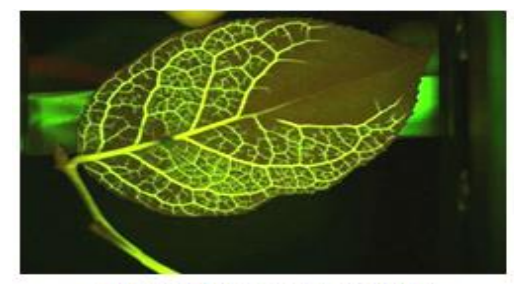

a) leaf with interconnected loops

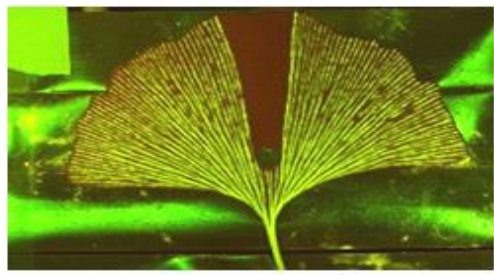

b) leaf without interconnected loops

Fig. 10. The difference between with natural and artificial fabrication

\subsubsection{The role of nature life principles in environmental adjustment}

To achieve this goal, it responses to meet the changing climatic conditions, that are measured using natural sensors. Nature living entities think and take optimum solution. Under changing environmental condition; the malleable, self-similar, replicated and customized natural form work as an actuator, it can relocate and resemble its elements to achieve low porous skin, a more or less permeable fabric that enable more or less entry of sun light [17].

Figure 11 explores living responsive surfaces ability to enhance environmental adjustment. Using self-similar scales that are interconnected in a continuous surface, varying in number, size, shape and thickness according to their function and position on the body. The biological thermoregulation behavior use adaptation and morphological changes to enable living organism to meet the changing environmental conditions. Using these characteristics, the building can be covered with special skin panels that can alter their orientation and dimensions. This promotes the translation of biological thermoregulation behavior into bio-kinetic architecture to help satisfy the users' need for a comfortable environment.
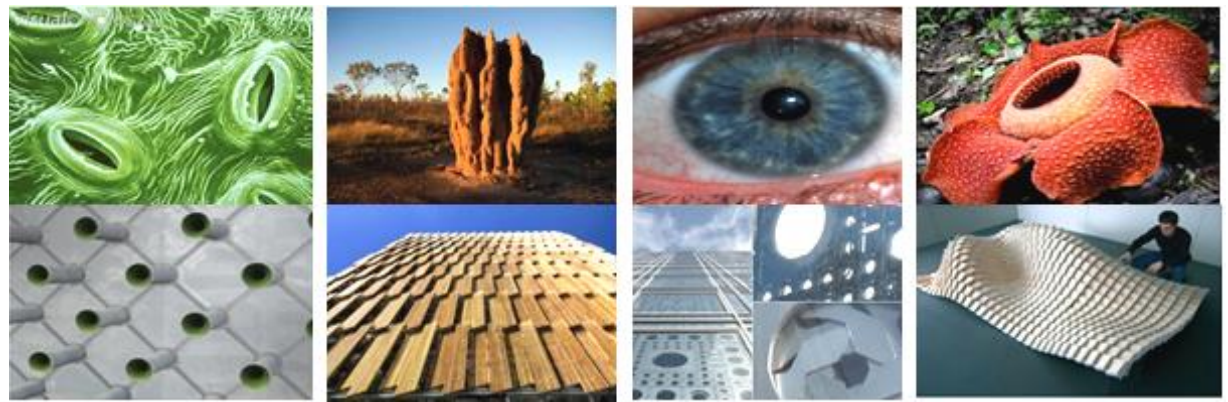

Fig. 11. Livable Responsive Surfaces Nature environmental adjustment

\subsection{Building inspired by nature in saving energy and resources}

Nature Optimize rather than maximize. Optimize is an act, process, and methodology to make nature reach the most perfect, efficient and effective as possible solution, in use, reuse, store, recycle, reserve, and gather resource (energy, water, materials, and wastes), with concerning the renewable energy and resources. Starting from the formation process, nature fit form to function. Second the evolution and adaptation process in response to short term changes. Finally, the growth and evolution process in response to long term changes. The form acts, develops, distributes and organizes, by responding to internal factors and external conditions. Architecture inspired by nature in such a manner.

Figure 12 explores living responsive surfaces ability to enhance saving energy and resources. Nature utilizes resources available locally with minimum embedded energy and 
recycles to maximum; just like the growth of tree or emulate natural forms like termite mound for passive systems to reduce cost and energy consumption. Its aerodynamic, Glazed shape minimizes wind loads and maximizes natural light and ventilation, reducing the building's energy consumption. Triangulations on the exterior similar to those of a glass sponge make the structure stiff enough to resist lateral structural loads without extra reinforcements.

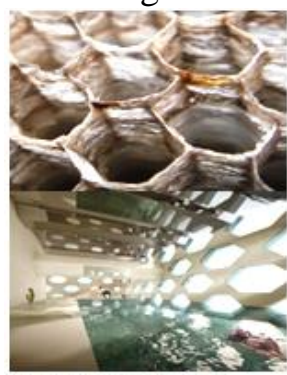

a) Enhancing Air flow

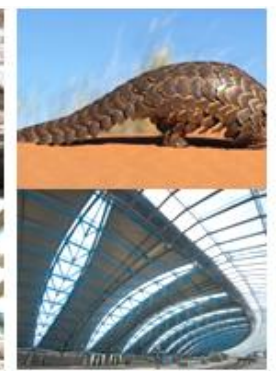

b) Structure stability

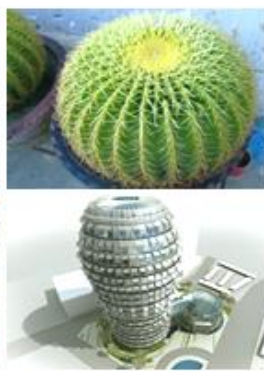

c) Regulate temperature

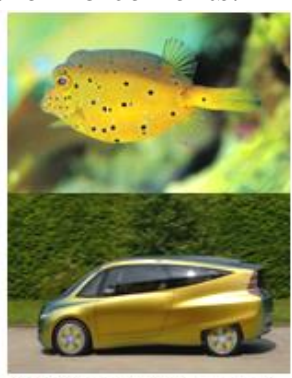

d) dynamics and resistance

Fig. 12. Energy efficient buildings

\subsection{Building inspired by nature as structure systems}

Nature Form is formed for the best function and transfer large amount of load with using the least material. Usually all natural structures have textural layers which cause these form changes under pressures and makes elastic or pressures reactions in them. On the other hand all the natural structures must be fixed when facing elastic physical powers and pressures [18]. Finings in his book "the anatomy of nature" says the structure evaluation in form is a wise reaction for living. In fact form and structure are the result of compromising with the environmental powers. Nature forms work with tension more than compression. Flexible structure systems through internal cores or external shells. Large \& clear unobstructed areas. Triangulated exoskeleton or frame inspired from glass sponge, thigh bone, beehive etc. or load distribution\& long span inspired by water lily or dragon fly wings. Ability to move in response to the imposed air pressure forces [19].

\subsubsection{Structure system paradigm shift (flat flow vs. free flow of loads)}

The non-Euclidian fractal form of nature flow of force, form is composed according to forces. This is to reduce material use. Self-similar, differentiated, and replicated natural form can provide structure solutions. Traditional industrial structure technology and systems that follow straight lines and flat slabs, it faces its poor resistance of bending and resistance of the flow of force, by increasing sheer volumes of resources and supporting members. In contrast, the world crises and low scares of materials, and more expensive structure cost, a natural efficient structure forms are preferred, that reduce consumption of resources. We learn from nature how the form is determined to reduce the forces that act on them [20].

\subsubsection{Fabrication}

Differentiation cause Continuous Vertical movement of materials and liquid. Malleability cause change according to force, and enable evolve and adaptation. With growth Most of nature living organisms have high dense fibers that have large amount of interconnected fabricated interconnected fibers to increase their stability and strength with low materials [14]. Linear cannot be reduced to linear sum, but nonlinearity of interconnected multifunction relations. Hexagonal structure uses the least material to create a lattice of cells with minimal surface area and the largest possible volume. Figure 13 explores how mimicking such concept to Building structure can achieve stability with minimizing material. 

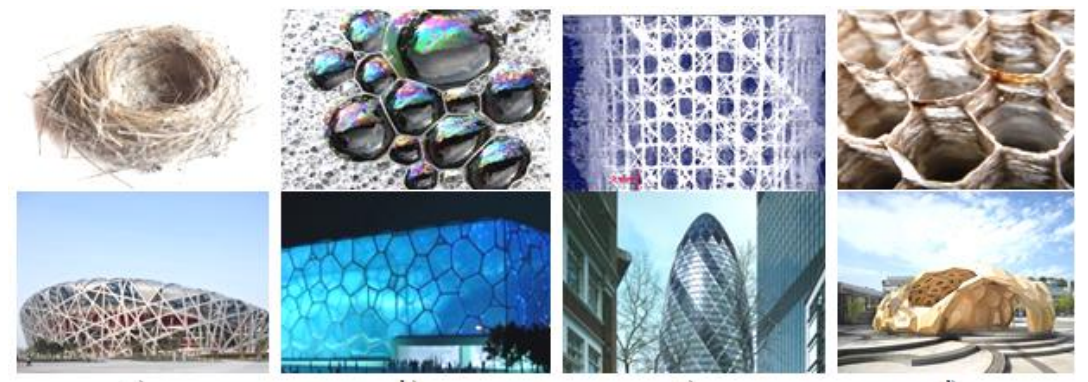

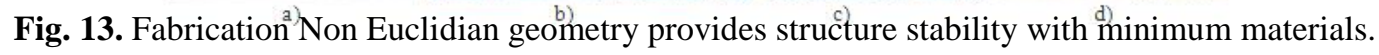

\subsection{Optimization vs. Maximization}

The self-optimization of nature form is not a linear process work to achieve efficiency of one function; rather it is a non-linear hierarchical, deeply organized system that enables nature to efficiently function to meet multi-functions requirements in the same time. Nature entities are optimized to act as efficient for multi- functions and multi-levels. Nature forms manifestation in architecture has typical objectives for a structure, movement flow and microclimatic environmental conditions are key to the generation process.

- Nature form behaves as function in environmental concerns to inform both the global shape and fibre articulation by creating apertures in the shell to allow in light and air.

- Nature form behaves as function in environmental concerns to regulate Solar exposure and displays the distribution and availability of incident solar radiation on the model and prevailing winds analysis defines the best possible position and shape of the openings to accommodate ventilation by avoiding strong light penetration.

- Nature form behaves as function in structure concerns to improve its structural behaviour, its strain energy, stress levelling and weight reduction while satisfying directional strength and stiffness. Both structural and environmental analyses are conducted to modulate the internal environmental conditions of the structure by reducing its stiffness.

To meet and respond to internal factors and external conditions, a Multifunctioning Material distribution analysis shows the areas with the least stress concentration, where material can be reduced to enable porous opening for wind and light penetration. Nature Form act, develop, distribute, and organize to shape the optimized solution through the way they are resembled and the system they interact. The optimum arrangement not only minimize load and pressure to the form, but also act to achieve maximum control on air and sunlight entry, and other environmental aspects. Also it enables the adaptation with changing condition of the environment.

To conclude, the sustainability of nature is rooted in both form and life principles. Nature form principles that used least material to achieve function requirements and fits form to function. On the other hand, this fractal form of customized entities of a whole provides malleability, thermodynamic, and it is resembled with actuation, adaptation and evolvement to achieve nature life; This form characteristics provide nature life in two ways the first is self-organizing behaviour, its adaptation and evolvement to meet the changing multi performance requirements, the second is complexity multi-layering, multifunctioning, organizational depth, non-linearity and non-hierarchic. These principles make nature achieve the self-optimized form and so adaptation to meet changing conditions of environment and so achieve sustainability. 


\section{Deducing modes of architecture manifestation of nature}

Many architects consider nature as a great professor that gives them different solutions for building problems, to build liveable buildings that behave in a self-sustaining process, so they manifest nature in architecture. The developed evaluation tools can be used to judge the power of logic behind architecture manifestation of nature, and to judge the architecture work that deserves respect from other useless surface manifestation of nature. Some architects manifest nature regarding its Aesthetics aiming to create new Form Oriented architecture. Other architects manifest nature regarding its Performance aiming to create new environmental, structural, functional and self-sustaining solutions.

There are different types of logic behind architecture manifestation of nature. In this section we have to distinguish between aims and tools of architecture manifestation. In first hand, manifestation aims range between Aesthetics (Form oriented) and function (Performance oriented) manifestation, as shown in Figure 14. In the other hand, manifestation tools range between form principles and life principles.
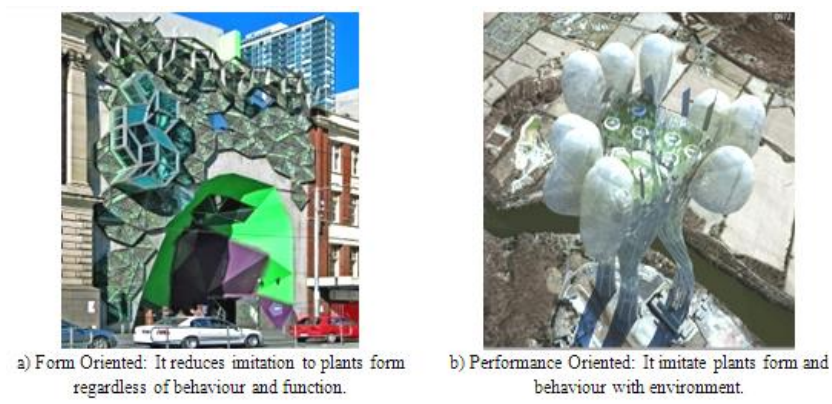

Fig. 14. Form oriented Versus Performance oriented manifestation of nature

In this sense, Table (3) builds a matrix between tools and concerns we can deduce four types of logic behind architecture manifestation of nature are deduced:

1- Using Form principles to achieve aesthetics oriented concerns.

2- Using Form principles to achieve performance oriented concerns.

3- Using Form and Life principles to achieve performance oriented concerns.

4- Using Life principles to achieve performance oriented concerns.

Table 3.

Deduced Modes of Architecture Manifestation of Nature

\begin{tabular}{|l|c|c|c|}
\hline \multirow{2}{*}{\multicolumn{1}{|c|}{ Concerns }} & \multicolumn{3}{c|}{ TOOLS } \\
\cline { 2 - 4 } & Form principles & Life principles & Form and life \\
\hline Form Oriented & 1 & & 4 \\
\hline Performance Oriented & 2 & 3 & 4 \\
\hline
\end{tabular}

These types can be distinguished using the right suffix that ranges between -morphic, logic, and -morphologic. The biology inspired architecture could range between Biomorphic, biologic and bio-morphologic; also the topology inspired architecture could range between topo-morphic, topologic and topo-morphologic.

\subsection{Biomorphic architecture (Bio-form)}

The biomorphic architecture is form oriented architecture. It reduces architecture manifestation to nature form principles and only form for Aesthetics concerns. Form 
becomes an aim in itself; it concerns how the form looks like regardless of how it performs to achieve its logic. Most of the time, it does not refer to a functional or ecological concerns. Due to the separation between the form and its performance, a fake logic is created; their architects concern materialistic formal values as shown in Figure 15.

It is now easy to be achieved under the evolution of natural science, it is easy to achieve the self-similar, replicating, differentiated, self-organizing, and non-Euclidian and fractal free-forms which can be seen in nature, especially with the evolution of math nature's geometry which cannot be abstracted by Euclidian geometry, can be explained by the help of fractal geometry. It is also related to the revolution in digital technology that makes it easy to achieve such non-Euclidian geometries.

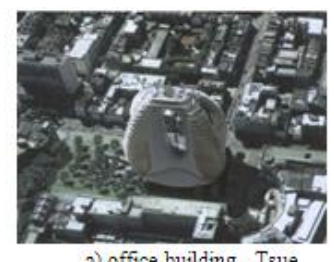

a) office building , Tsue http:/ www.arch.wsu.edu.

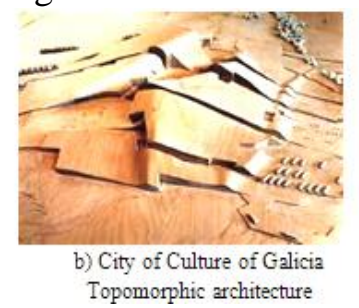

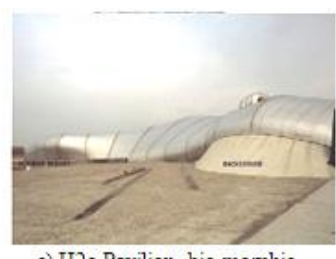

c) H2o Pavilion, bio-morphic architecture.

Fig. 15. Examples of Bio-morphic Approach: form becomes an aim in itself

Compared to the previous biomorphic approach, another biomorphic approach seemed to refuse using nature geometry principles and build its manifestation based on Euclidian geometry, self-sameness, difference and repetition techniques; this trend reduces architecture formal aesthetical manifestation of form principles in surface principles which make it loose the expression of the deep scientific understanding of nature geometry.

\subsection{Bio-logical architecture (Bio-Function)}

The biological architecture is performance oriented architecture. It aims to manifest nature form principles and only form principles for performance concerns. It refers to form finding for optimum performance transfer the process of emergence of a living entity to design thinking. Offers to observe and understand the functionality and harmony within nature. This approach refuses to reduce nature form in its aesthetics concerns, and extends it to how the form behaves to achieve its performance. But in the same time it neglects the life principles and accordingly it loose the power of nature adaptation and evolvement with changing conditions of the environment, as shown in Figure 16.
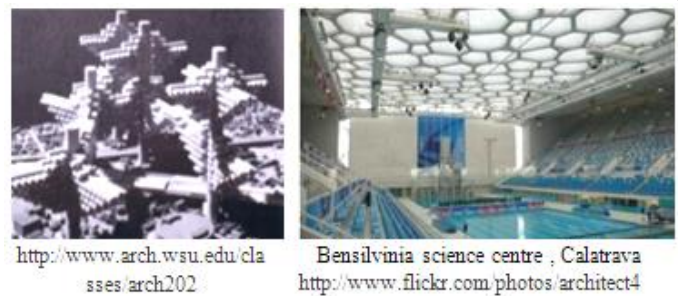

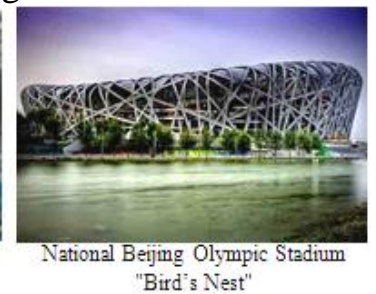

Fig. 16. Examples of Bio-logical Approach: function and behavior becomes an aim in itself.

\subsection{Bio-kinetic architecture (Bio-Function)}

The bio-self-kinetic architecture is performance oriented architecture. It aims to manifest only Life principles for performance concerns. It considers searching for nature form is poor and analogy based which restrict creativity and put it in a cast in. It borrows nature Life principles and focuses on kinetics, movement as an essential element in bio- 
Islam Ghonimi Ibrahim, The role of nature form versus life principles in achieving sustainability ...

mimicry to inform the design of the building. Their followers consider bio-kinetics as most essential face of bio-mimicry. They concerned the study of the kinetic aspects of biological systems - structure, function, and movement - to inform adaptive environmental approach of the design and engineering of buildings.

The process is an aim regardless it used the form to achieve the aim or not. Their followers refuse to reduce nature manifestation in their formal image and extend their manifestation to nature life, adaptation, and evolvement. This approach allows adoptability reaction awareness, control and responsiveness to the external environment such as air pressure, temperature, humidity, and radiation.

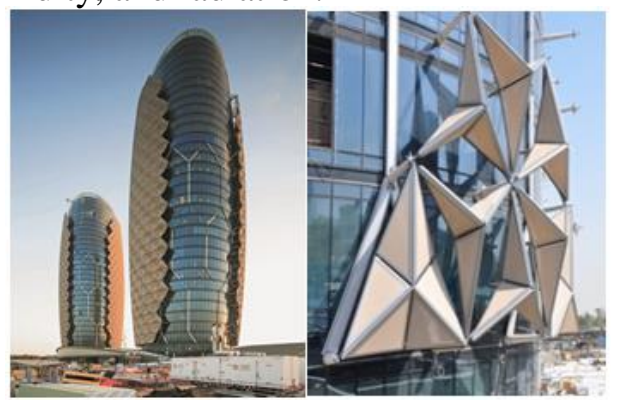

Fig. 17. Examples of Bio-kinetic approach: Form follows performance requirements

Compared with the previous fixed approaches, this kinetic approach is designed to respond to prevailing climatic conditions including solar radiation, daylight, wind and other factors, and for enhancing indoor environmental comfort levels, Figure 17.

It provides interactive concepts that gives smarter solutions and benefits efficient structures found in natural structural organizational and to benefits efficient behaviour with environment and create smart system save energy with an efficient comfort in use. It adapts and interacts with the surrounding environment and its variants including light, sound, wind, heat. This adaptation and interaction is done by some sort of transformation that does not require human assistance. Accordingly, it stimulates to utilize several architectural environmental applications such as; sun shading, sun breakers and windows. These tools enable architect to make sustainable built-environment that are inspired by nature. In this sense architects consider Nature as a great professor; as a database of solutions that already work.

\subsection{Bio-Kinetic-Morph-logic approach}

The bio-morph-logic architecture is performance oriented architecture; it aims to manifest both form and life principles for ethical and performance concerns. It considers both nature form and life principles at the same weight in achieving nature like performance buildings.

This approach depend on the form capabilities to give smarter solutions to benefit efficient structures found in natural structural organizational, and to benefit efficient environmental behaviour and to create smart systems to save energy with an efficient comfort in use. These forms allow adoptability reaction awareness, control and responsiveness to the external environment such as air pressure, temperature, humidity, and solar radiation, Figure 18. 


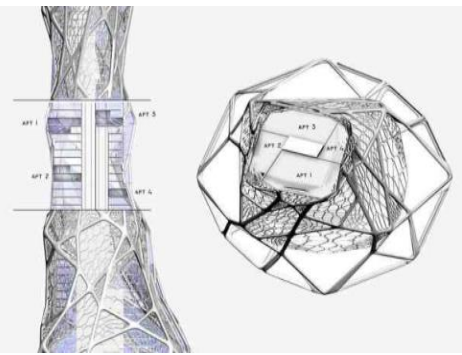

Fig. 18. Examples of Bio-morpho-logical approach: Form and life principles.

\section{Measuring the gap of the contemporary Egyptian practice of A.M.N}

In the last decade, the current architecture practice in Egyptian witnessed different trials to manifest nature; in this part, the developed criteria and classifications are used to test the gap of using form and life principles in relation to sustainability in Egypt. A set of criteria were developed based on the study's purposes; it contains form principles, life principles, sustainability concerns, and the deduced modes of architecture manifestation of nature.

\subsection{Determinates and standards}

The case study selection based on the following selection criteria: Samples selection to be Bio-inspired building; Developed in the last 15 years in (Egypt - Cairo); and to range of tools and principles utilizing the form and performance oriented concerns.

\subsection{Methodology}

The research uses the analytic descriptive methodology to identify and comprehend the selected case studies using the evaluation criteria, in order to identify the common characteristics that appeared well in most cases of Egyptian architecture that will affect the gap.

\subsection{Criteria analysis}

In this part the research applied criteria of architecture manifestation of nature in 4 dimensions the form principles, life principles, sustainability principle, and classification. The criteria are applied to selected case studies:-

a. Form Principles: Non-Euclidian Geometry, self-similarity, Replication, Differentiation, dynamics, and malleability.

b. Life Principles: Intelligence (sensor, think and control, actuation), holism, selforganization, adaptation, systemic complexity, interdisciplinary.

c. Sustainability Principles: Environmental adjustment, saving energy, environmental quality, optimization and adaptation.

d. Classification: Biomorphic, Biologic, Bio-morphologic, Bio-kinetic.

Table (4) presents the data gathering and analysis of applying the criteria to the selected case studies. The table presents the existence, value and type of each criteria of architecture manifestation in each dimension of nature for each project. The table provides a comparative analysis between the projects that is used to reach some kind of generalization about evaluation of Egyptian practice. Estimated ratios are deduced using sum and division factor for applying each criterion. It is compared to test the contradiction of the theory in Egypt. 
Islam Ghonimi Ibrahim, The role of nature form versus life principles in achieving sustainability ...

\section{Table 4.}

Case study data collection and analysis

\begin{tabular}{|c|c|c|c|c|c|c|c|c|c|c|c|c|c|c|c|}
\hline & Project 1 & Project 2 & \begin{tabular}{|l|} 
Project 3 \\
\end{tabular} & \begin{tabular}{|l|} 
Project 4 \\
\end{tabular} & \begin{tabular}{|l|} 
Project 5 \\
\end{tabular} & Project 6 & \begin{tabular}{|l|} 
Project 7 \\
\end{tabular} & \begin{tabular}{|l|} 
Project 8 \\
\end{tabular} & \begin{tabular}{|l|} 
Project 9 \\
\end{tabular} & & & & \multicolumn{3}{|c|}{ Evaluation of criteria } \\
\hline & Grand Museum & Stone Tower & \begin{tabular}{|l} 
Cairo Expo City \\
\end{tabular} & $\begin{array}{l}\begin{array}{l}\text { Zizinia } \\
\text { Compound }\end{array} \\
\end{array}$ & \begin{tabular}{|l}
$\begin{array}{l}\text { Medical park } \\
\text { premier }\end{array}$ \\
\end{tabular} & $\begin{array}{l}\text { Marcella group head } \\
\text { office }\end{array}$ & $\begin{array}{l}\text { Sama Marina - North } \\
\text { cost }\end{array}$ & \begin{tabular}{|l|}
$\begin{array}{l}\text { Busnis park - New } \\
\text { Cairo }\end{array}$ \\
\end{tabular} & \begin{tabular}{|l} 
Gate Residence \\
\end{tabular} & $\begin{array}{l}\text { El Rehab Mall- } \\
\text { New Cairo } \\
\end{array}$ & $\begin{array}{l}\text { Egypt solar slide } \\
\text { house }\end{array}$ & $\begin{array}{l}\text { DAR } \\
\text { Headquarter } \\
\end{array}$ & & 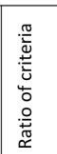 & 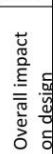 \\
\hline \multicolumn{15}{|l|}{ Form Principles: } & \multirow{10}{*}{$\begin{array}{l}60 \\
\%\end{array}$} \\
\hline Non-Euclidian Geometry & \multirow{9}{*}{$\begin{array}{l}v \\
x \\
x \\
x \\
v \\
v \\
v \\
x \\
v\end{array}$} & \multirow{9}{*}{$\begin{array}{l}\mathbf{v} \\
\mathbf{v} \\
\mathbf{v} \\
\mathbf{v} \\
\mathbf{v} \\
\mathbf{v} \\
\mathbf{v} \\
\mathbf{v} \\
\mathbf{v}\end{array}$} & \multirow{9}{*}{$\begin{array}{l}\mathbf{v} \\
\mathbf{v} \\
\mathbf{v} \\
\mathbf{v} \\
\mathbf{v} \\
\mathbf{v} \\
\mathbf{v} \\
\mathbf{v} \\
\mathbf{v}\end{array}$} & \multirow{9}{*}{$\begin{array}{l}x \\
x \\
x \\
x \\
x \\
x \\
v \\
x \\
x\end{array}$} & \multirow{9}{*}{$\begin{array}{l}\mathrm{x} \\
\mathrm{x} \\
\mathrm{x} \\
\mathrm{x} \\
\mathrm{x} \\
\mathrm{x} \\
\mathrm{x} \\
\mathrm{x} \\
\mathrm{x}\end{array}$} & \multirow{9}{*}{$\begin{array}{l}x \\
x \\
x \\
x \\
v \\
v \\
v \\
x \\
v\end{array}$} & \multirow{9}{*}{ 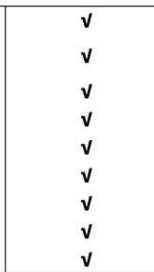 } & \multirow{9}{*}{$\begin{array}{l}\mathbf{v} \\
\mathbf{v} \\
\mathbf{v} \\
\mathbf{v} \\
\mathbf{v} \\
\mathbf{v} \\
\mathbf{v} \\
\mathbf{v} \\
\mathbf{v}\end{array}$} & \multirow{9}{*}{$\begin{array}{l}\text { v } \\
\text { v } \\
\text { v } \\
\text { v } \\
\text { v } \\
\text { v } \\
\text { v } \\
\text { v } \\
\text { v }\end{array}$} & \multirow{9}{*}{$\begin{array}{l}v \\
x \\
x \\
x \\
v \\
v \\
v \\
v \\
v\end{array}$} & \multirow{9}{*}{$\begin{array}{l}X \\
X \\
X \\
X \\
\text { V } \\
\text { V } \\
\text { V } \\
\text { V } \\
\text { V }\end{array}$} & \multirow{9}{*}{$\begin{array}{l}\mathbf{V} \\
\mathbf{v} \\
\mathbf{v} \\
\mathbf{v} \\
\mathbf{v} \\
\mathbf{v} \\
\mathbf{v} \\
\mathbf{v} \\
\mathbf{v}\end{array}$} & $8 / 12$ & \multirow{2}{*}{\begin{tabular}{|l|}
$70 \%$ \\
$50 \%$ \\
\end{tabular}} & \\
\hline $\begin{array}{l}\text { Avoid Rigid angles, corners, } \\
\text { Straight line }\end{array}$ & & & & & & & & & & & & & $6 / 12$ & & \\
\hline Avoid Rectilinear shapes & & & & & & & & & & & & & $6 / 12$ & $50 \%$ & \\
\hline Avoid Plain flat spaces & & & & & & & & & & & & & $6 / 12$ & $50 \%$ & \\
\hline Self-similarity & & & & & & & & & & & & & $10 / 12$ & $70 \%$ & \\
\hline Replication & & & & & & & & & & & & & $10 / 12$ & $70 \%$ & \\
\hline Differentiation & & & & & & & & & & & & & $11 / 12$ & $60 \%$ & \\
\hline Malleability & & & & & & & & & & & & & $8 / 12$ & $40 \%$ & \\
\hline Customization & & & & & & & & & & & & & $10 / 12$ & $40 \%$ & \\
\hline Life Principles: & & & & & & & & & & & & & & & \\
\hline Complex system & $\mathrm{x}$ & $\mathrm{x}$ & $x$ & $\mathrm{x}$ & $\mathrm{x}$ & $\mathrm{x}$ & $\mathrm{x}$ & $\mathrm{x}$ & $\mathrm{x}$ & $\mathrm{x}$ & $v$ & $\mathbf{v}$ & $2 / 12$ & $15 \%$ & \\
\hline Nonlinearity & $\mathrm{x}$ & $\mathrm{x}$ & $\mathrm{x}$ & $\mathrm{x}$ & $\mathrm{x}$ & $\mathrm{x}$ & $\mathrm{x}$ & $\mathrm{x}$ & $\mathrm{x}$ & $\mathrm{x}$ & $\mathbf{v}$ & v & $2 / 12$ & $15 \%$ & \\
\hline Deep organization & $\mathrm{x}$ & $\mathrm{x}$ & $\mathrm{x}$ & $\mathrm{x}$ & $\mathrm{x}$ & $\mathbf{x}$ & $\mathbf{x}$ & $\mathrm{x}$ & $\mathrm{x}$ & $\mathbf{x}$ & $v$ & v & $2 / 12$ & $15 \%$ & 15 \\
\hline Self-organization & $\mathrm{x}$ & $\mathbf{x}$ & $\mathrm{x}$ & $\mathrm{x}$ & $\mathrm{x}$ & $\mathrm{x}$ & $\mathrm{x}$ & $\mathrm{x}$ & $\mathbf{x}$ & $\mathrm{x}$ & v & v & $2 / 12$ & $15 \%$ & \\
\hline Adaptation Evolvement & $\mathrm{x}$ & $\mathrm{x}$ & $\mathrm{x}$ & $\mathrm{x}$ & $\mathrm{x}$ & $\mathrm{x}$ & $\mathrm{x}$ & $\mathrm{x}$ & $\mathrm{x}$ & $\mathrm{x}$ & $\mathbf{v}$ & v & $2 / 12$ & $15 \%$ & \\
\hline Growth & $\mathrm{x}$ & $\mathrm{x}$ & $\mathrm{x}$ & $\mathrm{x}$ & $\mathrm{x}$ & $\mathrm{x}$ & $\mathrm{x}$ & $\mathrm{x}$ & $\mathrm{x}$ & $\mathrm{x}$ & $\mathrm{x}$ & $\mathbf{x}$ & $0 / 12$ & $0 \%$ & \\
\hline \begin{tabular}{|l|} 
Sustainability concerns \\
\end{tabular} & & & & & & & & & & & & & & & \\
\hline Regulation of environment & $\mathbf{x}$ & $\mathbf{x}$ & $\mathbf{x}$ & $x$ & $x$ & $\mathbf{x}$ & $\mathbf{x}$ & $\mathbf{x}$ & $\mathbf{v}$ & $\mathbf{v}$ & $\mathbf{v}$ & $\mathbf{v}$ & $4 / 12$ & $35 \%$ & \\
\hline Saving Energy and resources & $\mathrm{x}$ & $\mathrm{x}$ & $\mathbf{x}$ & $\mathrm{x}$ & $\mathrm{x}$ & $\mathbf{x}$ & $\mathbf{x}$ & $\mathrm{x}$ & v & $v$ & $v$ & v & $4 / 12$ & $35 \%$ & 30 \\
\hline Structure conception & $\mathbf{v}$ & $\mathbf{v}$ & $v$ & $\mathrm{x}$ & $x$ & $\mathrm{x}$ & $\mathrm{x}$ & $v$ & $\mathrm{x}$ & $x$ & $v$ & $v$ & $6 / 12$ & $45 \%$ & $\%$ \\
\hline Save the environment & $\mathrm{x}$ & $\mathrm{x}$ & $\mathrm{x}$ & $\mathrm{x}$ & $\mathrm{x}$ & $\mathrm{x}$ & $\mathrm{x}$ & $\mathrm{x}$ & $v$ & v & $\mathbf{v}$ & $\mathbf{v}$ & $4 / 12$ & $30 \%$ & \\
\hline Optimize of multifunction & $\mathrm{x}$ & $\mathrm{x}$ & $\mathrm{x}$ & $\mathrm{x}$ & $\mathrm{x}$ & $\mathrm{x}$ & $\mathbf{x}$ & $\mathrm{x}$ & $\mathrm{x}$ & $\mathbf{x}$ & $v$ & v & $2 / 12$ & $15 \%$ & \\
\hline Design Concerns: & & & & & & & & & & & & & & & \\
\hline Form Oriented & $\mathbf{v}$ & $\mathbf{v}$ & $\mathbf{v}$ & $\mathbf{v}$ & 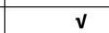 & $\mathbf{v}$ & $\mathbf{v}$ & $\mathbf{v}$ & 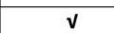 & $\mathbf{v}$ & $\mathrm{x}$ & $\mathbf{v}$ & $11 / 12$ & $80 \%$ & \\
\hline Performance Oriented & $\mathrm{x}$ & $\mathrm{x}$ & $\mathrm{x}$ & $\mathrm{x}$ & $\mathrm{x}$ & $\mathrm{x}$ & $\mathrm{x}$ & $\mathrm{x}$ & $v$ & $v$ & $v$ & $v$ & $4 / 12$ & $30 \%$ & 20 \\
\hline Fit form to function & $\mathrm{x}$ & $\mathbf{x}$ & $\mathrm{x}$ & $\mathrm{x}$ & $\mathrm{x}$ & $\mathbf{x}$ & $\mathbf{x}$ & $\mathbf{x}$ & v & $\mathbf{v}$ & $\mathbf{v}$ & $\mathbf{v}$ & $4 / 12$ & $30 \%$ & $\%$ \\
\hline Multifunction & $\mathrm{x}$ & $\mathrm{x}$ & $\ddot{x}$ & $\mathrm{x}$ & $\mathrm{x}$ & $\mathrm{x}$ & $\mathrm{x}$ & $\mathrm{x}$ & $\mathrm{x}$ & $\mathrm{x}$ & $v$ & v & $2 / 12$ & $15 \%$ & \\
\hline Evolve to change & $\mathrm{x}$ & $\mathrm{x}$ & $\mathrm{x}$ & $\mathrm{x}$ & $\mathrm{x}$ & $\mathrm{x}$ & $\mathrm{x}$ & $\mathrm{x}$ & $\mathrm{x}$ & $\mathrm{x}$ & $\mathbf{v}$ & $\mathbf{v}$ & $2 / 12$ & $15 \%$ & \\
\hline \begin{tabular}{|l} 
Approaches \\
\end{tabular} & & & & & & & & & & & & & & & \\
\hline Bio-morph (surface principles) & & & & $\sqrt{ }$ & $\checkmark$ & 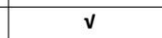 & & v & & & & & $4 / 12$ & $35 \%$ & \\
\hline Bio-morph (dcep principles) & $v$ & $\mathbf{v}$ & $v$ & & & & $\mathbf{v}$ & & & & & & $4 / 12$ & $35 \%$ & 15 \\
\hline Bio-logic & & & & & & & & & $\mathbf{v}$ & $\mathbf{v}$ & & & $2 / 12$ & $15 \%$ & $\%$ \\
\hline Bio-kinetic & & & & & & & & & & & $\mathbf{v}$ & $\mathbf{v}$ & $2 / 12$ & $15 \%$ & \\
\hline Bio-morphological & & & & & & & & & & & & & $0 / 12$ & $0 \%$ & \\
\hline
\end{tabular}




\subsection{Discussion}

After reviewing the previous analyses, the study found that there is a clear impact of the field of bio-mimic architecture in term of form and performance with varying values. A comparative analysis with summing the criteria scores and getting their ration to all ample is used to test the application of each criterion. Following is a discussion of the result of the analytical study; contains measure of the gap, the deduced key points of weakness and recommendations to enhance the practice.

\subsubsection{Measure of the gap}

The evaluation reveals that there is a wide gap between Egyptian architecture and theory of mimicry; the evaluation distinguishes architecture that deserves respect from architecture that is useless:

1- It reveals low level (40\%) of using nature form principles, and very low level (15\%) of using nature life principles, the matter that explore weakness of applying the theory of bio-mimicry especially the one related to life, movement, adoptability, evolvement and growth.

2- It reveals low level of performance oriented manifestation (20\%) in reference to form oriented one $(80 \%)$ using life principles, the matter that explores weakness of concerns.

3 - It revealed equal percentage (50\%) of deep form principles and surface form principles that explore how extent the manifested forms are far from nature geometry.

4- It reveals the adopted approaches that range between biomorphic (70\%), biologic $(15 \%)$ and Bio kinetic (15\%).

The previous analysis concludes the wide gap between theory of bio-mimicry and the Egyptian contemporary practice exists.

\subsubsection{The points of weakness}

The evaluation deduced key points of weakness and recommendations to enhance the practice:

5- Reducing the manifestation of nature to form oriented concerns and neglect the performance oriented concerns. They achieve aesthetical appealing forms; that expresses the current state of technological and scientific development. On the other hand they neglect the performance requirements, as shown in Figure 19.

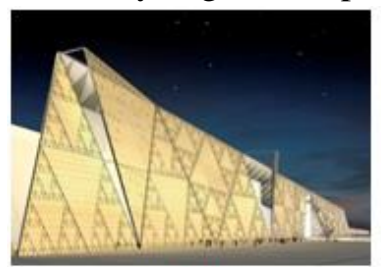

a) Grand Museum

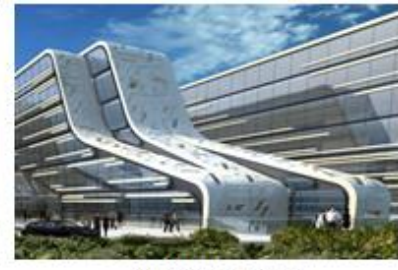

b) Stone Tower

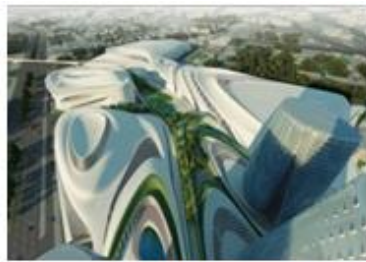

c) Cairo Expo City

Fig. 19. Reducing manifestation to formal concerns

6- Reducing form oriented concerns to surface form principles, and avoid using deep form principles. This restrict manifestation to use Euclidian geometry with rigid forms, corners, acute angles, and straight lines, this make the manifestation loss the power of expressing the current evolution in scientific and digital technology techniques, as shown in Figure 20. 


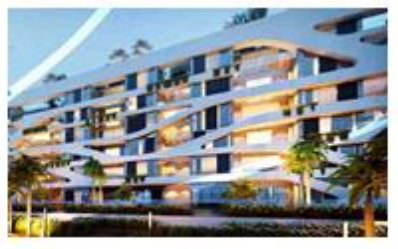

a) Diama - zizinia compound new Cairo

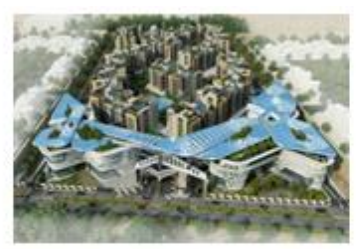

b)Akoya compound-new Cairo

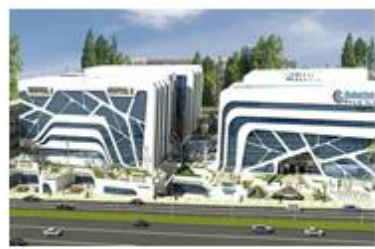

c) Medical park premier - new Cairo

Fig. 20. Reducing manifestation to Euclidian geometry and neglecting the power of nonEuclidian geometry

7- Reducing form to using Euclidian geometry with rigid angles, corners, acute angles, and straight lines, flat space this make the manifestation loss the power of expressing the current evolution in scientific and digital technology techniques, as shown in Figure 21.

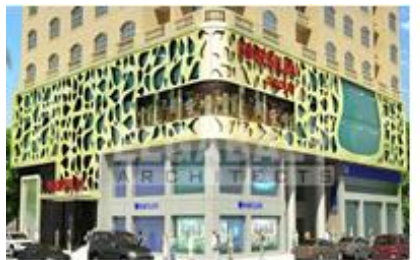

a) Marcella group head office

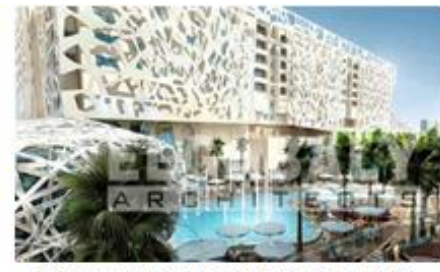

b) Genena Commercial Park, Nasr City

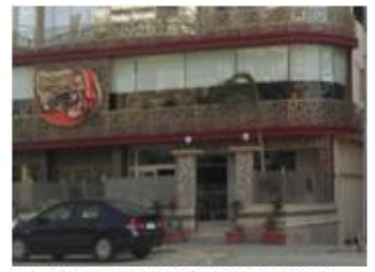

c) Tanoreen coffee shop, Roxi.

Fig. 21. Reducing manifestation of nature to Euclidian and flat spacing

8- Reducing the form oriented architecture to use traditional computer techniques based on manual form modelling, and avoids using script oriented techniques based on form finding inside nature; the matter make it much far from the real nature form, as shown in Figure 22.

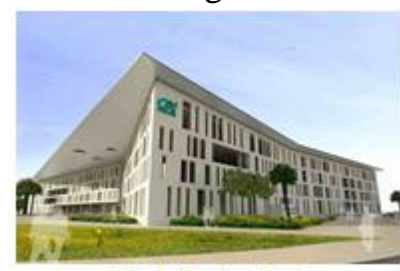

a) Credit Agricole bank

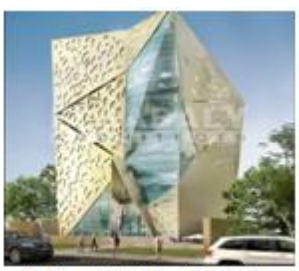

b) Crystal Mall - New Cairo

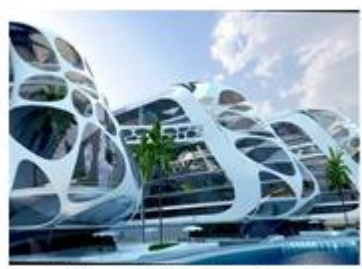

c) Same Marina - North cost

Fig. 22. Reducing manifestation of nature to form modeling and avoid form finding

9- Reducing the performance oriented manifestation to form principles; and neglect life principles this make the manifestation loss the power of adaptation, evolvement, and responsiveness to meet the environmental changing conditions, as Shown in Figure 23.

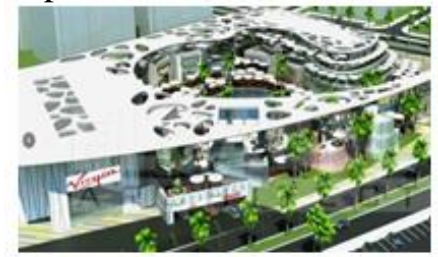

a) El Rehab Mall - New Cairo

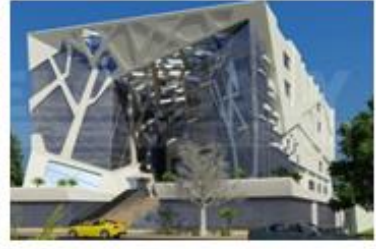

b) Busnis park - New Cairo

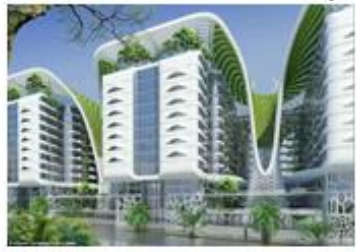

c) Gate Residence

Fig. 23. Reducing manifestation of nature performance to form principles and neglect life principles 


\subsubsection{Recommendations to enhance Egyptian practice of nature manifestation}

After reviewing the previous analysis and defects of contemporary Egyptian architecture, following are some recommendation to enhance practice of bio-mimic architecture, Figure 24:

1- Extending architecture manifestation beyond form oriented architecture, and including to performance oriented as well, this will insure the role of bio-mimicry in achieving sustainability in architecture.

2- Extending the form oriented architecture beyond surface manifestation and expressing the deep principles, architects need to express the non-Euclidian, selfsimilar, replicated, differentiated principles.

3- Extending the performance oriented manifestation beyond form principles through fitting form to function and extending manifestation to use life principles to achieve a bio-kinetic approach to sustainability, using life adoptability and evolvement to changing conditions.

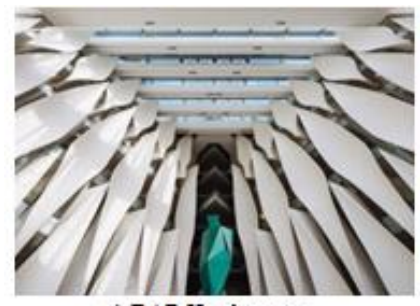

a) DAR Headquarter

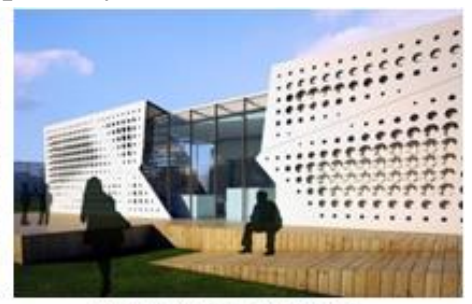

b) Egypt solar slide house

Fig. 24. Extending manifestation to form and life principles for formal and performance concerns

\section{Conclusion}

The study revealed the importance of bio-mimicry as a contemporary philosophy to architecture design and a way of achieving sustainability. The study investigated the complexity of nature form and life principles as follows:

- Nature Form complexity revealed the following principles: self-similarity rather than self-sameness, Replication rather than Repetition, Differentiation rather than difference, Malleable rather than rigidity and customization rather than production.

- Nature life complexity revealed the following principles: it is not simple form but complex system; it is not linear but parallel with multiple non-linear interdependent nonhierarchical; It does not concern single function but it concerns multifunction for structure, environmental, aesthetic, and other functions in the same time; It is not dependent entity rather it is Interdependent, Cooperative; It is not controlled rather it is self-organized to achieve equilibrium; It is not fixed rather it is adoptive, evolving and growing to survive and meet the changing conditions of the ecosystem.

- Nature has Form with a morphological complexity that has life and behavior, to meet performance requirement to meet the changing conditions of the system in which it exist and grow. Nature responses to change, by sensor, To achieve this; nature need to have Biological sensing devices for Heat, light, and wind conditions so different Thermophysical and optical principles of nature Sensors are used; secondly, thinking and response systems in nature with optimization of the most perfect responses are applied; finally, Actuation and movement using malleability and thegmo-morphogenesis principles. This enables nature to adapt of form to meet the changing conditions. 
The study revealed the role of both nature form and life principles in achieving sustainability, starting from fitting the form to function, secondly, the role of nature life to act, develop, distribute, and organize, by responding to short term changing conditions of the internal system and external eco system; and long term evolution through the growth process to meet the long term changes of the ecosystem. Finally, nature optimizing rather maximizing of the least required material and energy.

- Nature form finding is not about aesthetics; rather it is about the form finding for the optimized system for structure, environmental, energy saving, and other performance requirements, and optimized solutions using self-organized adoptive solutions to achieve equilibrium.

- The study revealed Four Modes of Architecture manifestation of nature, range based on their concern to form versus performance oriented architecture and the form versus life principles. They are bio-morphic, bio-morph-logic, bio-kinetic, and Bio-logic.

The study measured the gap of Egyptian architecture manifestation of nature and revealed the wide gap of contemporary architecture manifestation and points of defects and provided recommendations to enhance the Egyptian practice of nature oriented architecture.

- Compared to old manifestation Architects should not reduce their manifestation of nature to the deep nature form principles to create new architecture forms. They should extend their manifestation of nature to the deep nature life principles to create new environmental, structural, and functional solutions.

- They should extend nature beyond form principles or shape or what it is made of, or how it looks like, or replicating the natural forms. They should concern about life principles, the intelligence of the system, the way nature resembled, and acts, and the rules governing those forms. It is not about how to emulate nature form; it is about how to emulate nature process.

- Manifestation of nature is not a question of form finding for aesthetical concerns; rather it should be for performance concerns.

\section{REFERENCES}

[1] Harun Yahya, Biomimetics: Technology Imitates Nature.: Global Publishing, 2007.

[2] Janine M. Benyus, Biomimicry: Innovation inspired by nature., 2002.

[3] Benoit B. Mandelbrot, The Fractal Geometry of Nature. New York: W.H. Freeman and Company., 1982.

[4] Islam Ghonimi, "Architecture Manifestation of Nature scintific paradigm shift," Journal of Al-Azhar University Engineering Sector, 2011.

[5] Husein A., "Self- similarity as a cosomic limitation and its effects in interior space formation," in 100 year of creativity 2010, Egypt, 2010.

[6] Daniel E. Koshland Jr, "The Seven Pillars of Life, ," Science 295, pp. 2215-2216, 2002.

[7] "Chase, Jacobs \& Aquilano 2006, p. 419".

[8] F. G. Asenjo, In-between: An Essay on Categories.: University Press of America, 1988.

[9] Francis Heylighen, "THE SCIENCE OF SELFORGANIZATION AND ADAPTIVITY," in Knowledge management, organizational intelligence and learning, and complexity, The encyclopedia of life support systems.. UK: Eolss, 1999.

[10] Alexander Backlund, "The definition of system," Kybernetes, vol. 29, pp. 444-451, 2000. 
[11] Nicolas Salingaros, The Structure of Pattern Languages.: Architectural Research Quarterly volume 4., 1999.

[12] Nikolas Salingaros, "Architecture, Patterns, and Mathematics," in A THEORY OF ARCHITECTURE. Umbau-Verlag, Solingen, Germany, 2006, pp. 75-85.

[13] Christopher Alexander, "A City Is Not A Tree," Architectural Forum, Vol 122, No 1, pp. 58-62, April 1965.

[14] Sakthivel Ramaswamy and Konstantinos Karatzas Maria Mingallon, Fibre Composite Adaptive Systems / Architectural Association.: unpublished theises as part of master degree, architecture association, London, 2012.

[15] Po-Yu Chen Marc André Meyers, Biological Materials science: Biological materials, Bioinspired materials and biomaterials.: Cambridge University Press, 2014.

[16] Michael Graham Richard. (2010, march) Awesome Biomimicry: Leaf Veins Inspire New Model for Water and Electricity Distribution Networks. [Online].

[17] Jialiang Wang, Liliana O. Beltrán, and Jonghoon Kim, "From Static to Kinetic: A Review of Acclimated Kinetic Building Envelopes".

[18] Mehdi Kavandi, Alireza Jozepiri, Sharareh Teimouri and Fatemeh Abbasi Mehdi Sadri, "Bionic Architecture, Forms and Constructions," Research Journal of Recent Sciences, march 2014.

[19] Hagan S., "Taking Shape: A New Contract between Architecture and Nature," Architectural Press, St. Louis, USA, 2001.

[20] Joshua Anthony, Biomimicry of Orchids: Lessons in structural form for the built environment. Geelong: Deakin University, Geelong, Australia, 2010.

\footnotetext{
${ }^{1}$ http://biomimicry.net/ \& http://biomimicry.org/_\& http://www.asknature.org/
} 


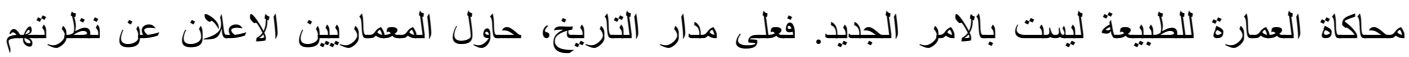

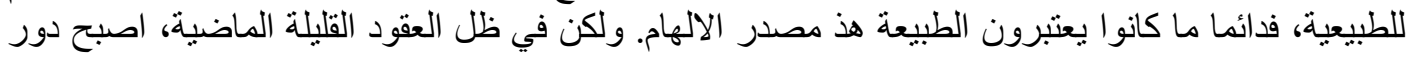

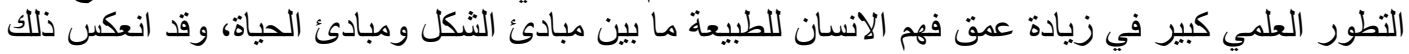

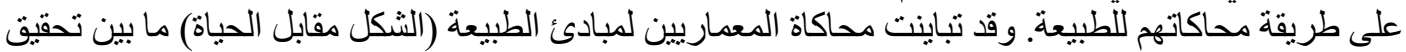

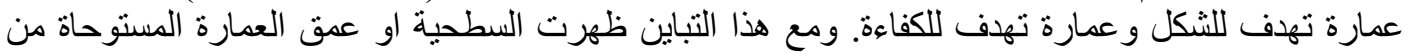

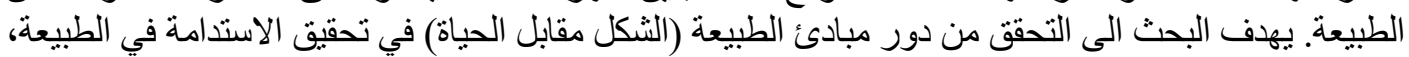

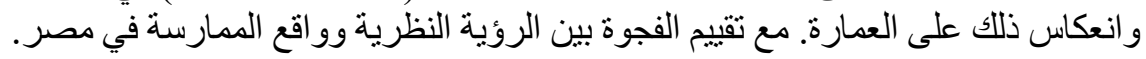

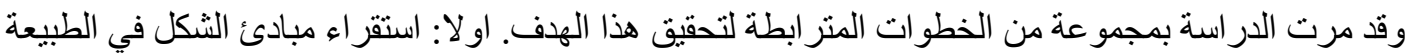

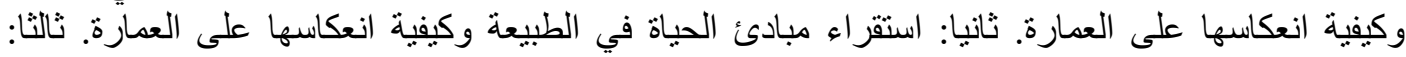

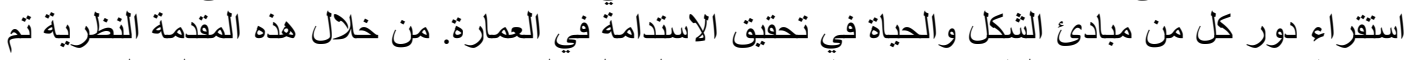

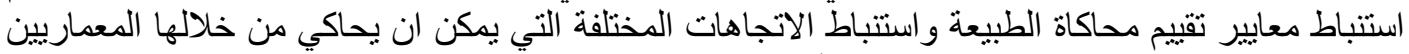

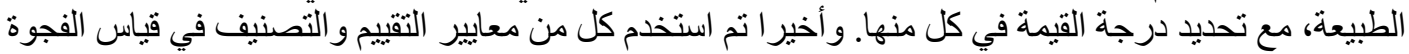

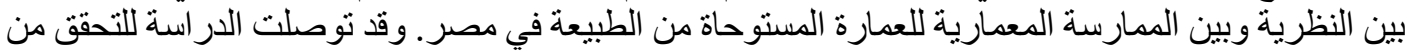

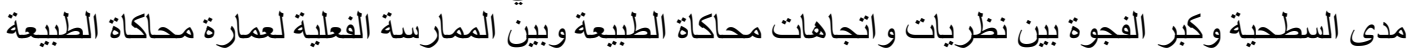

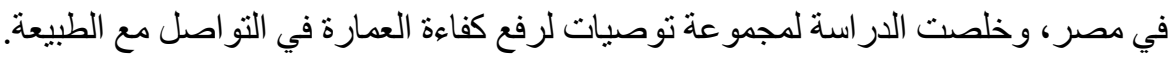

